\title{
Marine litter from beach-based sources: Case study of an Eastern Mediterranean coastal town
}

\author{
Michelle E. Portman ${ }^{a}$, Ruth E. Brennan ${ }^{a, b}$ \\ a Technion - Israel Institute of Technology, Faculty of Architecture and Town Planning, \\ Technion City, Haifa 3200003, Israel \\ ${ }^{b}$ Centre for Environmental Humanities, School of Histories and Humanities, Trinity \\ College, Dublin 2, Ireland
}

This is the accepted manuscript of a paper originally published in Waste Management. You may find the final, formatted version at 10.1016/j.wasman.2017.07.040.

\section{Abstract}

Marine litter has been a serious and growing problem for some decades now. Yet, there is still much speculation among researchers, policy makers and planners about how to tackle marine litter from land-based sources. This paper provides insights into approaches for managing marine litter by reporting and analyzing survey results of litter dispersal and makeup from three areas along an Arab-Israeli coastal town in view of other recent studies conducted around the Mediterranean Sea. Based on our results and analysis, we posit that bathing beach activities should be a high priority for waste managers as a point of intervention and beach-goers must be encouraged to take a more active role in keeping beaches clean. Further, plastic fragments on the beach should be targeted as a first priority for prevention (and cleanup) of marine litter with plastic bottle caps being a high priority to be targeted among plastics. More survey research is needed on non-plastic litter composition for which amounts and geographic dispersal in the region vary greatly from place to place along Mediterranean shores. In general, findings of this study lead us to recommend exploring persuasive beach trash can design coupled with greater enforcement for short term waste management intervention while considering the local socio-economic and institutional context further for long-term efforts.

\section{Introduction}

Marine litter requires immediate attention from waste managers and waste planners (Ryan, 2015). It is a growing problem worldwide, with myriad consequences for both environmental and public health (Derraik, 2002; Gregory, 2009), especially as development along coasts increases and populations are more reliant on coastal, and especially beach areas for economic and social well-being.

Many countries are trying to address the problem of marine litter from land-based sources, particularly along beaches. Some are doing so on a local or national level (Chen, 2015). However, it is clear that coordinated transnational efforts must be made in view of the 
transitory and ubiquitous nature of marine litter; once litter is in the oceans it is very hard to collect and remove. This is especially well-known in the Mediterranean Sea which is a semienclosed sea with a very slow flush rate; large populations live along its coasts and environmental awareness among many of these inhabitants is not particularly high (Laubier, 2005). Efforts to address the acute problems of beach litter by the 22 countries on the Mediterranean seashores are beginning to take shape, albeit slowly (Alkalay et al., 2007; Laglbauer et al., 2014; Poeta et al., 2014; Munari et al., 2016; Poeta et al., 2016; Pasternak et al., 2017).

On the international level, marine debris has been addressed by recent global declarations such as "The Future We Want" (UN General Assembly, 2012), and by more focused efforts such as the The Honolulu Strategy (UNEP/NOAA, 2011) and the EU's strategy on plastics, as described in Action 9 of the EU Joint Communication on International Ocean Governance (EU, 2016). A major effort in preventing and addressing marine litter from various sources has been the Marine Strategy Framework Directive 2008/56/EC (MSFD) (European Parliament, 2008). The MSFD established a framework for each Member State of the EU to take action to achieve or maintain Good Environmental Status (GES) for the marine environment by 2020. Number ten of the eleven "descriptors" of GES requires that "Properties and quantities of marine litter do not cause harm to the coastal and marine environment". Other conventions and agreements that address marine litter problems specifically are MARPOL and the Barcelona Convention in the Mediterranean region and the Bucharest Convention, the Helsinki Convention, and OSPAR in other regions.

To address the problem of marine litter, waste managers and planners need to be clear about what it is and where it comes from; in other words, they need information about its generation and dispersal. While several studies have conducted surveys and identified a variety of activities generating marine litter (e.g., Slavin et al., 2012;, Alkalay et al., 2007; Poeta et al., 2014; Munari et al., 2016) the novelty of this paper is its surveying of litter found on a coastal area within a single town over time and space. Although all three of the spaces surveyed are beaches, different activities take place in each. This paper links to the qualitative study, Brennan and Portman (2017), conducted at the same case study site and draws insights from it to address the specific types of litter found.

Marine litter is commonly defined as "any persistent, manufactured or processed solid material discarded, disposed of or abandoned in the marine and coastal environment" (Galgani et al., 2010). It reaches the oceans through deliberate disposal or unintentional discharge, either at sea or from land by way of rivers, drainage systems and wind (UNEP/MAP, 2012). Thus, marine litter can be broadly categorized as land-based (originating on land) or marine-based (originating at sea). The former comes mostly from agricultural, industrial and recreational activities whereas the latter originates mostly from fisheries, boating and shipping (UNEP, 2009).

Estimates of the exact portion of marine litter originating on land vary somewhat. Reports from Greece classify land-based litter (69\%) and vessel-based waste (26\%) as the two predominant 
sources of litter with fisheries making up the remainder (Koutsodendris et al., 2008). Slavin et al. (2012) similarly found that $77.5 \%$ of litter on beaches in Tasmania, Australia had a landbased origin, compared with $22.5 \%$ from marine sources. But by and large it is clear that a significant amount of marine litter comes from land-based sources (Thiel et al., 2013).

Therefore, a number of marine litter studies have pointed out the need for up-to-date, detailed and contextual research that focuses on landside inputs, such as the recreational activities taking place on beaches (Alkalay et al., 2007; Slavin et al., 2012; Laglbauer et al., 2014; Munari et al., 2016).

There is particularly great importance associated with under-standing how beach activities influence marine litter in the Mediterranean Sea region where the bathing season is long and beaches are generally crowded and close to population centers (European Commission, 2016; Pasternak et al., 2017). As a case in point, in an early study of marine litter along Israeli beaches, Golik and Gertner (1992) concluded that the makeup of the litter surveyed suggested it was left by beach goers. Many more recent studies of coastal waters in other parts of the world have come to similar conclusions (e.g., Thiel et al., 2013).

Further, much of the most problematic litter, due to its persistent qualities, is plastic (e.g., Barnes et al., 2009; Gregory, 2009) which has often been found to be left by beach goers (e.g., Slavin et al., 2012; Poeta et al., 2014). This plastic adds to the general amounts of plastic expected to reach the oceans in the near future from landside activities. A mega-study conducted by Jambeck et al. (2015) estimated that between 4.8 and 12.7 million metric tons of plastic waste alone entered the oceans in 2010 from land-based sources. The authors of that study estimate that the amount of plastic waste that will enter the marine environment from land- based sources will increase by an order of magnitude by 2025 .

This paper reports on and analyzes surveys of coastal litter dispersal and makeup in view of other recent research efforts in the region and beyond. Our case study along Israel's Mediterranean coast surveyed beach cleanliness under varying spatial and temporal conditions. Litter types were reported using two sampling regimes: one comparing three study sites with different activities and the other focusing on litter composition. Thus we seek answers to questions about: (i) the quantity and distribution of marine litter at different locations along the beach; (ii) landside coastal activities that contribute to near-shore marine litter; and (iii) the predominant debris materials found along the shore at the study site in relation to other bathing beaches surveyed in the Mediterranean Sea basin. We address these questions using a comparative empirical research design which compares results to previous studies and seeks to draw conclusions about what kind of management actions would be most appropriate to reduce marine litter generated on coasts.

\section{Methods}

Depending on how they are designed, litter counts can reflect the presence, amounts and types of marine debris. Evaluative sampling of nearshore marine litter reflects the long-term balance between inputs, land-based sources or stranding, and the processes of export, input, burial, degradation and cleanups. Factors influencing densities and whereabouts of litter, such as 
cleanups, storm events, rainfall, tides and hydrological changes may alter litter counts and influence the evaluation of fluxes in nearshore marine waters. Even if surveys can track changes in the composition of litter in coastal waters, they are sometimes not sensitive enough to monitor minor changes in overall abundance (Galgani et al., 2015). This problem can be addressed to some extent by recording the rate at which litter accumulates on beaches, through surveys per-formed at logical temporal and spatial intervals while controlling for some influencing factors in a single geographic region.

Keeping these factors in mind, we used two different measures for our survey of litter at the case study town of Jisr-Az-Zarqa (hereafter "Jisr"): (1) the Clean Coast Index (CCI); and (2) littertype monitoring. The first is a measure of beach cleanliness that has been used by previous marine litter studies in the Mediterranean context (Alkalay et al., 2007; Laglbauer et al., 2014; Munari et al., 2016). We used the $\mathrm{CCl}$ to compare littering behaviors at different points along Jisr's one and a half kilometer coastline which reflect different beach-going activities. The $\mathrm{CCl}$ is a useful method for surveying bathing beach cleanliness that is increasingly being used due to its straightforward approach, feasibility, objectivity, and suitability to Mediterranean beaches (see Alkalay et al., 2007). Also, its frequent past and current use (in the sources mentioned above) renders the results of this study comparable to those of studies taking place in other locales.

We used the second measure to understand beach litter composition in the town at two different points in time at Jisr's officially designated bathing beach, before and after opening of the swimming season. Official "bathing beach" areas are those designed in a land use plan, dedicated to recreational beach activities, particularly swimming. During the swim season, which lasts from approximately mid-May to the end of September, lifeguard services are provided by the local municipality and funded at least in part, by the national government. This second measure follows a protocol that conforms with the recommended minimum requirements for beach litter monitoring that implements the MSFD and is based on recommendations from the European Commission-mandated Technical Subgroup on Marine Litter (TSG-ML, European Commission, 2013). The Technical Subgroup on Marine Litter recommendations are based on the OSPAR Commission Guidelines for Monitoring Marine Litter on the Beaches in the OSPAR Maritime Area (OSPAR, 2010), UNEP Operational Guidelines for Comprehensive Beach Litter Assessment (Cheshire et al., 2009) and the NOAA Marine Debris Shoreline Survey Field Guide (Opfer et al., 2012; European Commission, 2013).

\subsection{Sampling sites}

We sampled during the late spring and summer months at three sites within the municipal borders of Jisr when rainfall in the Eastern Mediterranean region is virtually non-existent and other weather-related factors are minimal. The town of Jisr (Fig. 1) is the only exclusively Arab village along Israel's $190 \mathrm{~km}$-long Mediterranean shore and its coast is relatively undeveloped. While along the country's shoreline there are a number of small- scale fishing ports in several towns (such as Akko and Jaffo), only Jisr has maintained an exclusively artisanal fishery. Litter 
management in the town is known to be problematic and there is already some understanding of the underlying issues and context of how the local population approaches the waste problem (see Brennan and Portman, 2017).

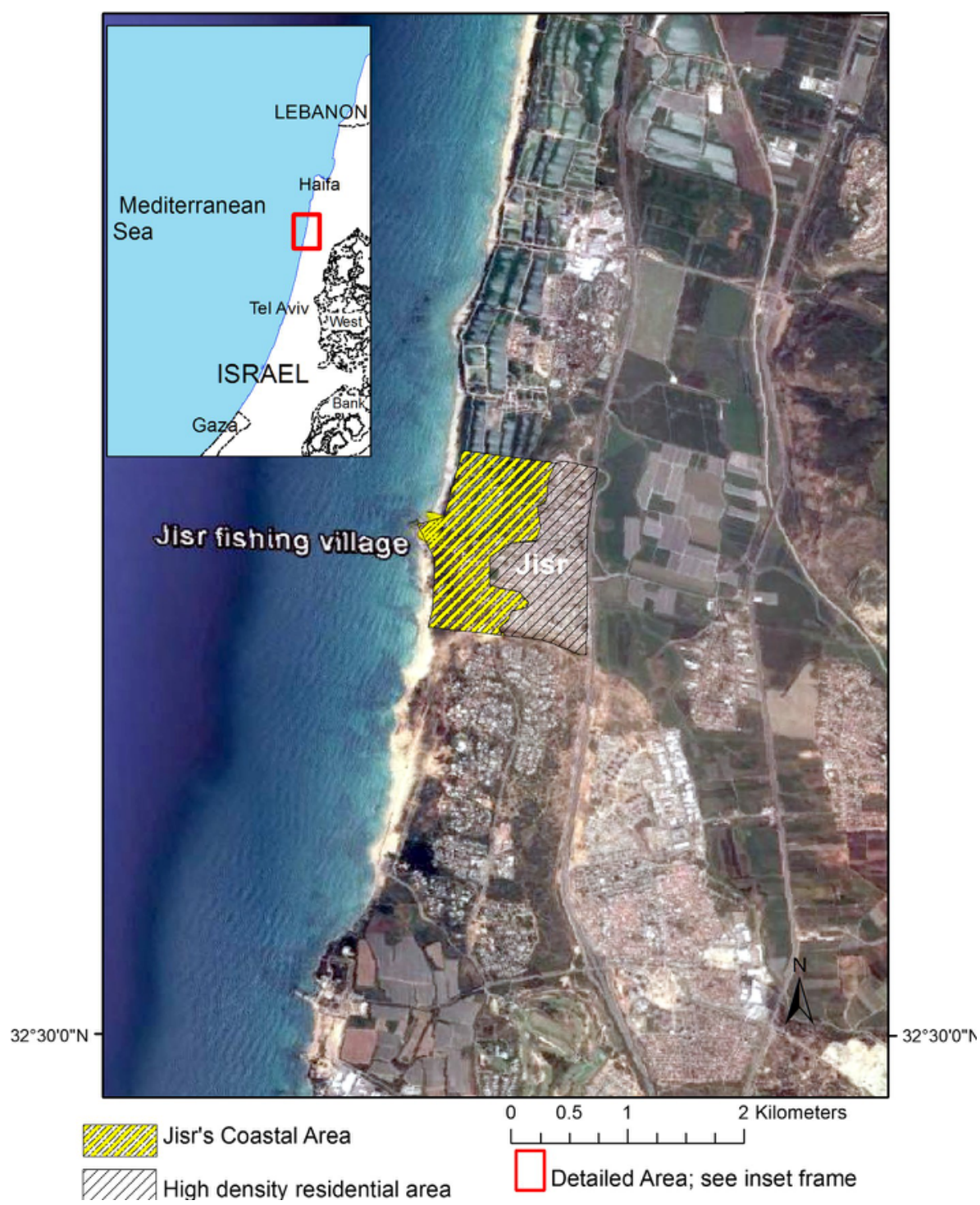

Figure 1. General locus map (orthophoto source: Google Earth).

The town's shoreline is composed of sandy beaches and shallow lagoons, some rocky headlands and kurkar ${ }^{1}$ cliffs with sandy dunes covering the low backshore. Nearshore submerged areas consist of rocky reef habitat and abrasion platforms flanked by a small bay. Geographically, Jisr is an appropriate research site since Mediterranean Sea litter studies have found that nearshore litter is concentrated in shallow coastal areas rather than in deeper waters (Koutsodendris et al., 2008) and in bays more than in open areas (UNEP/MAP, 2012; Galgani et al., 2015). For this reason, and those mentioned in the previous paragraph, the particular time and place was chosen for the case study. 
${ }^{1}$ Calcareous aeolianite (kurkar) interspersed with red loamy paleosol (hamra) units form ridges in the northern coastal plain of Israel. These ridges are rapidly eroding and suffering from over-development.

Economically distressed and densely populated, Jisr's population consists of 13,400 residents within a very limited space $\left(1.6 \mathrm{~km}^{2}\right)$. Its residential neighborhoods are distanced from the seashore so that beach activities are somewhat isolated. Jisr is home to one of Israel's poorest communities, with town residents falling in the lowest out of ten socio-economic clusters (CBS, 2013). Despite the town being somewhat of a socio-economic outlier, it is well-located between two major cities (Tel-Aviv and Haifa) and adjacent to a major tourist attraction, the ancient Roman-era port of Caesarea. Most importantly, efforts are underway to bring more tourists to the village, including through the development of its artisanal fishing village for ecotourism (Kamisher, 2015; Arlozorov, 2016).

The particular sites for sampling, denoted respectively as A, B, C, were chosen for the discrete activities taking place on them (see Table 1, Fig. 2 and Supplemental Material Fig. D.1 that includes photographs of each of the three sites): the fishing village beach (Segment $A$; artisanal and recreational fishing activity), the undeveloped beach (Segment B; extensive recreation) and the bathing beach (Segment C; intensive recreation). The most northward Segment A includes a hill rising to about $10 \mathrm{~m}$ and largely submerged abrasion tables seaside of the shore; it also includes the area of the fishing village on which a few huts are located on the landward side of the shallow lagoons and small bay. We sampled the sandy southern half of Segment $A$ in front of the huts. Segment B is the largest; it is similar low-sloping sandy beach (as in the fishing village) but with a backdrop of low vegetation. Extensive recreation occurs here consisting mainly of walking and hiking. By contrast, the officially designated bathing beach (Segment C) has constructed facilities including a bathroom and a changing building, wooden sun-shelters, an outdoor shower and a raised shack from which lifeguard services are provided during the bathing season (See Fig. D.1).

Table 1. Characteristics of the sampled areas.

\begin{tabular}{|l|l|l|l|l|}
\hline Sites (north to south) & $\begin{array}{l}\text { Segment length } \\
\mathbf{m} \text { (north-south) }\end{array}$ & $\begin{array}{l}\text { Beach depth } \\
\mathbf{m} \text { (west-east) }\end{array}$ & Activities & $\begin{array}{l}\text { Total } \text { area }^{\mathbf{a}} \\
\text { sampled }\left(\mathbf{m}^{\mathbf{2}} \text { ) }\right.\end{array}$ \\
\hline Fisherman's beach (A) & 20 & $6.3-47.0$ & Fishing; social gatherings & $63-470$ \\
\hline Undeveloped Beach (B) & 30 & $8.8-41.7$ & Extensive recreation & $88-417$ \\
\hline Bathing beach (C) & 20 & $20.8-63.0$ & Intensive recreation & $208-630$ \\
\hline
\end{tabular}

${ }^{\text {a }}$ Sampled area length (north to south) is constant (10 m delineated as 5 two-meter long sections) while depth changed for each sampling session. Note: A-C as in Fig. 2. 


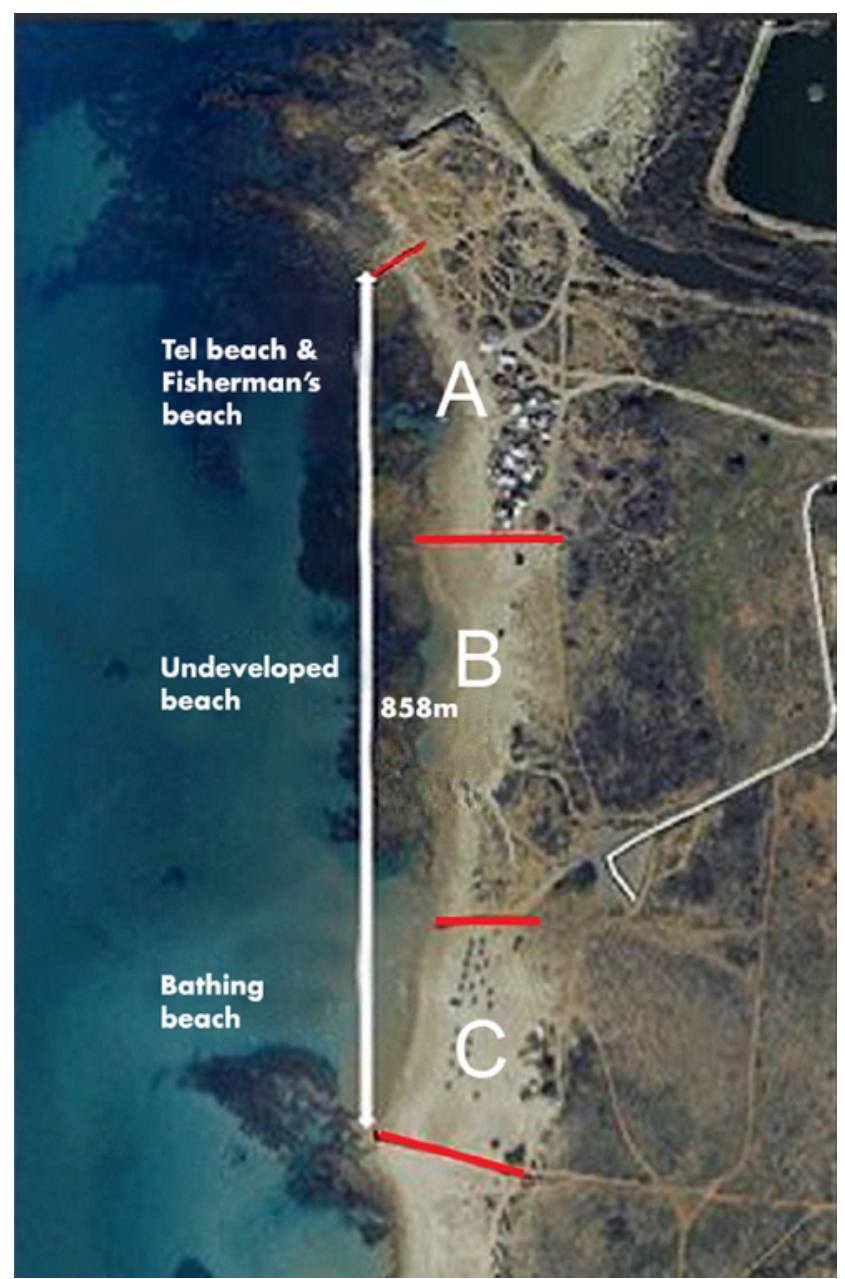

Figure 2. For sampling, we divided the Jisr beach into 3 sections: (A) the tel (hill) and fishermen's beach; (B) the undeveloped beach; (C) the bathing beach. Orthophoto. Source: www.govmap.gov.il

\subsection{Sampling and analysis}

The sampling for determination of the $\mathrm{CCl}$ occurred every two weeks (from the end of April through July 2016). These sampling times included two surveys done before and five during the swim season, for a total of seven sampling periods. The temporal variance reflects fluctuations in beach-goers and paid clean-ups that started to occur on all the beaches after the swim season officially opened in early June.

The $\mathrm{CCl}$ as developed by Alkalay et al. (2007) indicates the level of beach cleanliness. It uses ranks ranging from "Clean" to "Extremely Dirty" (see range (from 0 to 20+) as listed in caption of Fig. 3). Calculation of the index is as follows:

$$
C C I=\left(\frac{\text { Total litter on transect }}{\text { Total area of transect }}\right) \times K
$$

The index gives the number of plastic litter items counted per square meter of the transect area which is the product of the transect length and depth. Consistent with the $\mathrm{CCl}$ index calculation 
(as set out in Alkalay et al., 2007), we applied the coefficient $\mathrm{K}=20$ as a multiplier (see the above formula) to ensure that the value of the resulting index would not fall between 0 and 1 . This was done in all previous applications of the $\mathrm{CCl}$ method (e.g., Laglbauer et al., 2014; Munari et al., 2016), including for its original use and application on Israeli beaches (see Alkalay et al., 2007). Transects are delineated from the water's edge at the time of measuring and they extend to the first landside obstacle encountered when walking upland from the water's edge (e.g., sand dune, cliff, vegetation, road or fence). As is common when using the CCI method, the area of the beach surveyed at each site changed somewhat each time surveying was conducted, mostly as a result of changes in tide. The minimum size restriction for plastic litter counted $(2 \mathrm{~cm})$ is in keeping with recommendation for litter monitoring as presented in Alkalay et al. (2007) and Abu-Hilal and Al-Najjar (2004). Also, this minimal size was adhered to in order to avoid the need for additional micro-plastic measuring methods which must be applied for "small" litter items (i.e., <2 cm).

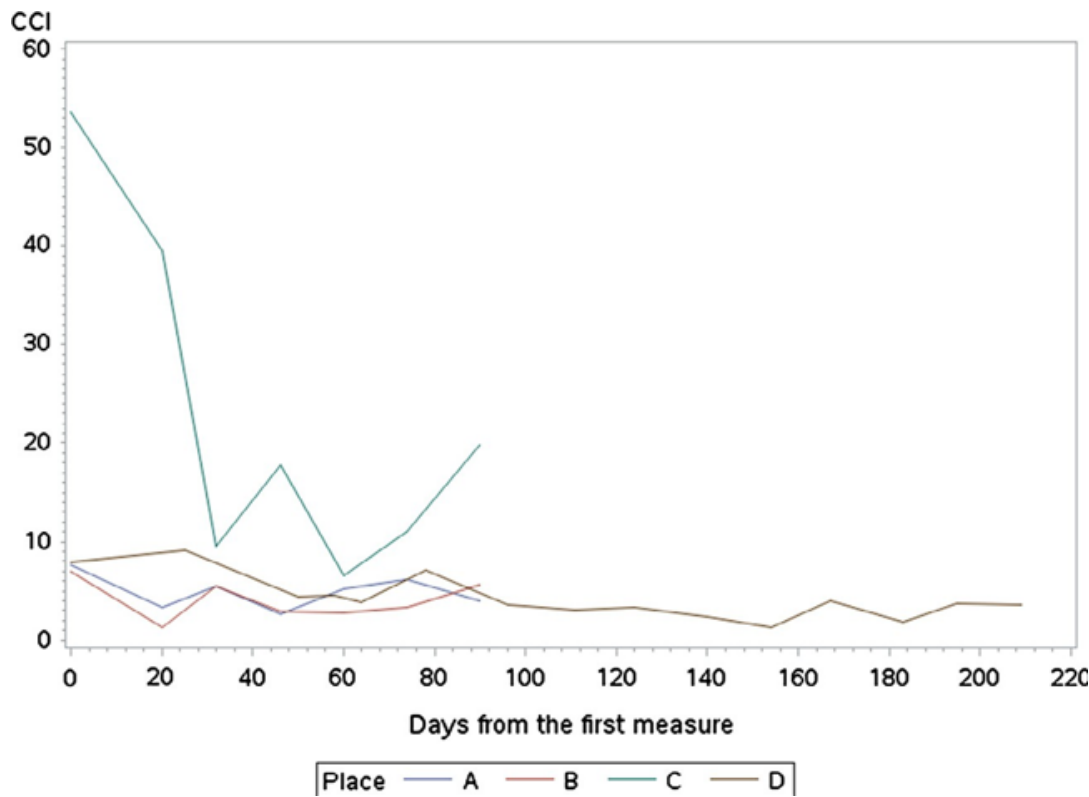

Figure 3. CCl time trend for sites A, B, C (April and July inclusive) and D (from Alkalay et al., 2007) by days from first measurement throughout the late spring and summer season (see values in Table 2). Note: $\mathrm{CCl}$ categories: 0-2 Very clean; 2-5 Clean; 5-10 Moderate; 10-20 Dirty; 20+ Extremely dirty.

The second sampling measure informs about the quantity and type of materials (i.e., the "detailed survey") found on a portion of the Jisr bathing beach (within Segment C). For this we conducted a detailed survey once before the swim season began and once during the swim season. In contrast to the $\mathrm{CCl}$, the detailed survey was not limited to sampling of plastic litter alone (see Supplemental Material Table B.1). As noted above, the method used for the detailed survey is based on the minimum requirements for beach litter monitoring within the MSFD, as recommended by the Technical Subgroup on Marine Litter (European Commission, 2013). The TSG-ML recommends a minimum survey length of $100 \mathrm{~m}$ on a low to moderate slope with clear beach access, at least two sections of $100 \mathrm{~m}$ in length on the same beach on lightly to moderately littered beaches and at least two sections of $50 \mathrm{~m}$ in length for heavily littered beaches (European Commission, 2013). However, the short Jisr bathing beach limited the 
sampling to an area of one section of $10 \mathrm{~m} 20.8 \mathrm{~m}$ (a total of 208 meters square). Although quarterly surveying is recommended by the TSG-ML (European Commission, 2013), due to time and budgetary limitations we measured at the end of April (before swim season) and the end of July (during the swim season). For consistency, as recommended, the detailed surveying was conducted on the same portion of the bathing beach both times.

We used the MSFD Master List Recording Form (European Commission, 2013) to record litter items and we classified litter items according to 49 types of material organized into 9 major groups (See Supplemental Materials Table B.1). Identification and classification are based on the MSFD Master List (European Commission, 2013), considering the 165 categories referring to beach litter. This allowed us to assign each litter item to a standard General Code (hereafter GC) as described by the Master List (European Commission, 2013). The Master List was developed as part of a technical (non-legally binding) guidance document with recommendations for monitoring marine litter in accordance with the MSFD, one of the descriptors of the GES. ${ }^{2}$ The use of this system for categorization allowed the statistical comparison of our data to results reported by Munari et al. (2016) and Poeta et al. (2016), who also conducted recent surveys of litter on bathing beaches of the Mediterranean using this system.

The methods used in this study allow two unique contributions. Firstly, the methodology applied allows a comparison of beach cleanliness using the $\mathrm{CCl}$ index for different sites within Jisr over a short-term time frame and using Alkalay et al. (2007) as a long-term benchmark. Secondly, the methodology provides data for a statistical comparison of beach litter composition on the Jisr bathing beach with results reported from two recent beach litter surveys in other Mediterranean countries (i.e., Munari et al., 2016; Poeta et al., 2016). Results of both the surveys themselves and of the statistical comparisons are reported in the next section. The discussion presents the interpretation of the results and their waste management implications.

${ }^{2}$ European Commission Decision 2010/477/EU identified four different indicators for Descriptor 10: (i) trends in the amount of litter washed ashore and/or deposited on coastlines; (ii) trends in the amount of litter in the water column; (iii) trends in the amount, distribution, and, where possible, composition of micro-particles; (iv) trends in the amount and composition of litter ingested by marine animals (Poeta et al., 2016).

\section{Results}

In regards to the cleanliness of the beach in Jisr, our CCl data show that the bathing beach is consistently dirtier than the other two sites sampled (see Table 2 and Fig. 3). The bathing beach (Segment C) became significantly cleaner once the bathing season began in mid-May, when it maintained a clean to moderate $\mathrm{CCl}$ level. This is despite a large volume of visitors due to the warmer weather and lifeguard services available once the swim season began. However, the $\mathrm{CCl}$ at the bathing beach is consistently higher (indicating a dirtier beach area) than the other two locations ( $A$ and $B$ ); the significance of this difference is confirmed by statistical analysis, even when compared to the previous (benchmark) study of $\mathrm{CCl}$ indices in Israel from years past as explained below. 
Table 2. The items of litter counted at each of the A. B and C sites (see Fig. 2) surveyed as well as the dimensions of the area surveyed (in square meters) during each of the time periods, semi-weekly April through July. The number of litter items counted is used for calculating the Clean Coast Index (CCI).

\begin{tabular}{|c|c|c|c|c|c|c|c|c|c|c|c|c|c|c|c|c|c|c|c|c|c|}
\hline \multirow{2}{*}{$\begin{array}{l}\text { Survey } \\
\text { period } \\
\text { Segment }\end{array}$} & \multicolumn{3}{|l|}{1} & \multicolumn{3}{|l|}{2} & \multicolumn{3}{|l|}{3} & \multicolumn{3}{|l|}{4} & \multicolumn{3}{|l|}{5} & \multicolumn{3}{|l|}{6} & \multicolumn{3}{|l|}{7} \\
\hline & A & $\mathrm{B}$ & C & A & $\mathrm{B}$ & C & A & B & C & A & B & C & A & B & C & A & B & C & A & B & C \\
\hline Litter count & 24 & 133 & 557 & 62 & 6 & 741 & 53 & 30 & 121 & 13 & 61 & 448 & 24 & 30 & 72 & 48 & 31 & 161 & 29 & 39 & 622 \\
\hline Area $\left(\mathrm{m}^{2}\right)$ & 63 & 378 & 208 & 380 & 88 & 375 & 192 & 110 & 252 & 100 & 417 & 504 & 93 & 218 & 220 & 157 & 190 & 293 & 470 & 138 & 630 \\
\hline Density $^{\mathrm{a}}$ & 0.38 & 0.35 & 2.68 & 0.16 & 0.07 & 1.98 & 0.28 & 0.27 & 0.48 & 0.13 & 0.15 & 0.89 & 0.26 & 0.14 & 0.33 & 0.30 & 0.16 & 0.55 & 0.06 & 0.28 & 0.99 \\
\hline $\mathrm{CCI}^{\mathrm{b}}$ & 7.61 & 7.03 & 53.6 & 3.26 & 1.36 & 39.5 & 5.52 & 5.45 & 9.6 & 2.6 & 2.92 & 17.77 & 5.16 & 2.75 & 6.55 & 6.11 & 3.26 & 10.98 & 3.94 & $\begin{array}{l}5 . \\
65\end{array}$ & 19.74 \\
\hline
\end{tabular}

${ }^{a}$ Density is the item $/ \mathrm{m}^{2}$. The number is rounded to two decimal places.

bote: CCl categories: 0-2 Very clean; 2-5 Clean; 5-10 Moderate; 10-20 Dirty; 20+ Extremely dirty.

It is likely that the cleaner status as the season progressed at all three sites is related to the fact that there were some scheduled clean ups occurring once the bathing season began. The municipality employs a worker to pick up trash and empty bins on Jisr's bathing beach (C). Since the beginning of May 2016, the Israel Nature and Parks Authority employed three local fishermen to collect trash from the other two beaches ( $A$ and $B$ ) as the municipality is no longer responsible for these beaches. As cleaning occurred on all 3 beaches, the sites should be comparable (see Brennan and Portman, 2017). However, we received conflicting information about when the cleanups began occurring and how regularly they occurred on the bathing beach; according to some town officials the cleaning of the bathing beach occurred erratically, especially during the first few weeks of the bathing season.

The results of the $\mathrm{CCl}$ data can be compared to other studies of the entire coast of Israel in the past (Alkalay et al., 2007) as well as a more recent study by Pasternak et al. (2017) although this latter study, which focused only on the types of litter found on beaches, used a different categorization system. Data collected from June to December of 2005 resulted in CCI measures for 39 different beaches along Israel's Mediterranean coastline including the Jisr beach (Alkalay et al., 2007). The aim of 2005 study (published in 2007) was to illustrate the use of the CCl methodology for assessing changes over time as municipalities joined a national government initiative, called the Clean Coast Program that included beach cleanups and awareness raising activities implemented by the municipality. Overall, as in our study, cleanliness generally improved at the 59 sites sampled over a 200-day period in 2005; at the Jisr site, the $2005 \mathrm{CCl}$ data points went from 7.92 down to 3.66 over a period from June to December.

To compare the recent $\mathrm{CCl}$ calculations for locations $\mathrm{A}, \mathrm{B}$ and $\mathrm{C}$, with past data calculated and reported by Alkalay et al. (2007), we add the latter as an additional series, called D (see Fig. 3). We see a linear trend that was fitted to all 4 curves which indicated as expected, a significant negative slope for site $C$ and no time changes for the other locations. The average value over time was highest for $C$ (Least square mean $=11.83, p=0.0005)$, then for $D$ (Least square mean $=$ $5.16, p=0.007)$. The least square means for sites $A$ and $B$ were not significantly different from 0 (Least square mean $=4.45, p=0.15$; Least square mean $=3.80, p=0.21$, respectively). However, the least square means comparisons between the three locations $A, B$ and $D$ did not indicate a significant difference. Indeed, when we fitted a model without $C$, we found no significant differences among the three sites $A, B$, and $D$. The graphical display shows a decrease over time for location $D$, but one that is not strong enough to reach statistical 
significance (see Supplemental Material B for detailed tables showing the results of the statistical analysis).

In regards to measures of litter composition (see Fig. 4), our sampling and that of other past studies of Mediterranean beaches using the same materials categorization, show both similarities and differences. Our surveying showed that the majority of the litter on the Jisr bathing beach was plastic (79\% in April; 76\% in July), yet significant differences were found when we used the Pearson's Chi-Square test to compare the two time points $(p=0.002)$. The Chi-square test indicates how likely the fit between the observed differences between data sets results from chance (when comparing between the two points in time or between the different studies). Differences were more pronounced when the Chi-square test was applied without the data on plastic (See Appendix A and B). Accordingly, the main changes were decreases between April and July in cloth and paper, but an increase in foam packing and "Other" category was also apparent.

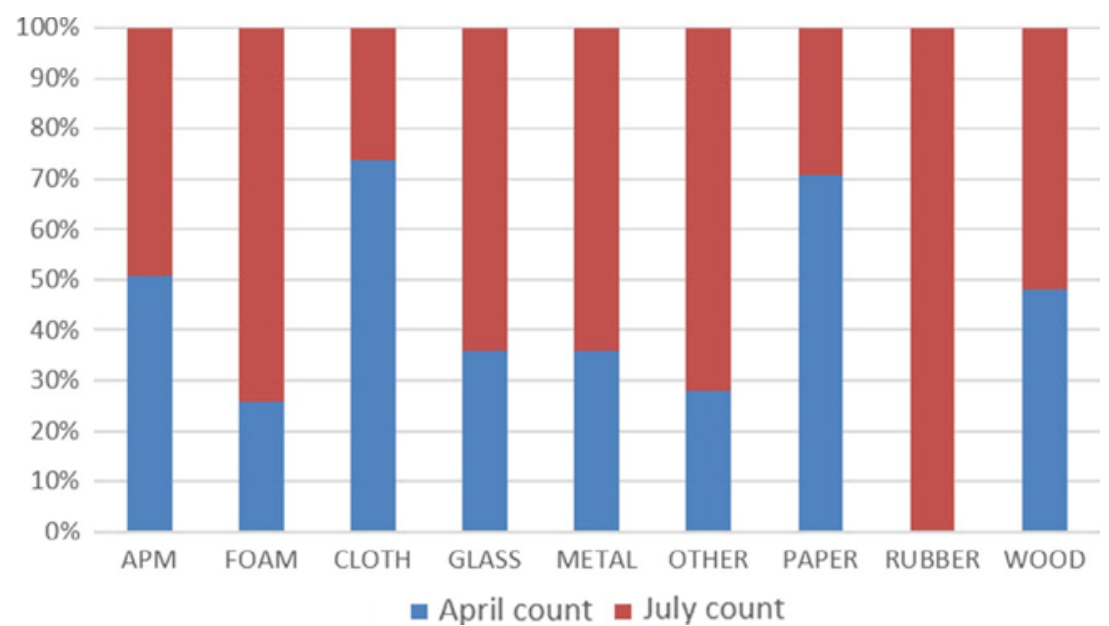

Figure 4. Materials collected on the Jisr bathing beach (at site $\mathrm{C}$ ) during the two sampling periods categorized by type (according to Cheshire et al., 2009). Note: APM = Artificial polymer material (plastic).

As mentioned, both the Munari et al. (2016) and Poeta et al. (2016) used the same materials categorization we used and therefore comparisons of the studies' results could be made. The former study involved a survey of litter composition, spatial distribution and sources of litter at five bathing beaches on the north-western Adriatic coast of Italy in 2015. The latter assessed marine litter at three beach sites along the Tyrrhenian coast of central Italy from Spring 2014 to Winter 2015. While proportions of plastic were $78 \%$ for the Jisr data overall considering the two sampling periods together (See Fig. 5), plastic made up $81 \%$ and $97 \%$ for Munari et al. (2016) and Poeta et al. (2016) respectively. For Munari et al. (2016), the highest proportion, without plastic was paper (37\%); for Poeta et al. (2016) the highest proportion without plastic was metal (30\%). The greatest amounts of non-plastic litter found on the Jisr bathing beach (See Fig. 6) were cloth (25\%) and wood (25\%). (For details on this part of the analysis see Appendix C.)

Overall, the chi-square tests were highly significant indicating differences among the locations and the times $(p<0.002)$ for three sets of data compared. The significant differences were 
more pronounced when the Chi-square test was applied without the data on plastic indicating that despite similarity in beach activities (i.e., bathing beach recreational activities),

distributions of the litter composition were quite different, beyond the fact that plastic makes up the largest portion of litter in all data sets (See Supplemental Materials, Appendices 2 and 3).

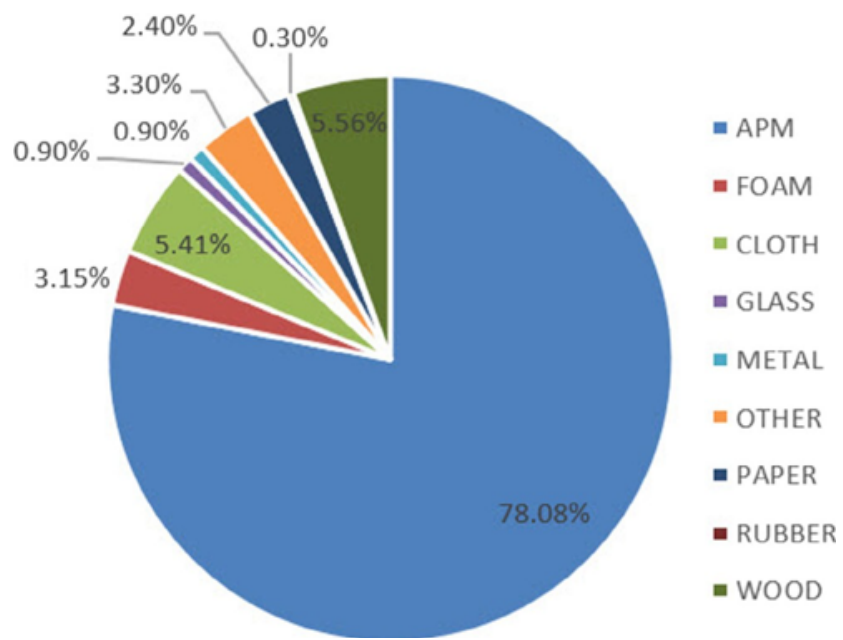

Figure 5. Distribution of litter by type using the total number of materials collected on the Jisr bathing beach $(N=666)$.

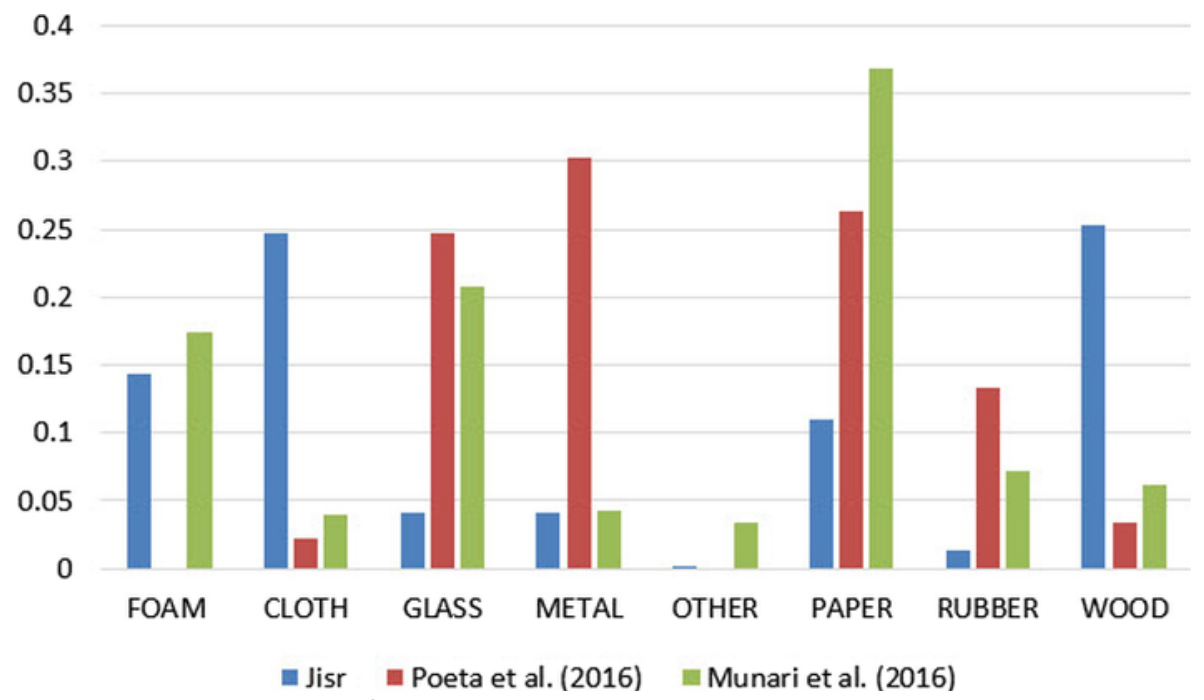

Figure 6. Percentages of non-plastic litter materials counted in the current Jisr study, Poeta et al. (2016) and Munari et al., 2016.

\section{Discussion}

Our discussion considers both the location of the greatest amount of litter within the entire case study area (the Jisr coastal area, Segments A-C) and the makeup of that litter as measured at the bathing beach site (Segment $\mathrm{C}$ ). Our findings coincide with what other researchers and studies have found both in terms of beach dirtiness and the high variability of beach litter composition, other than plastics. From the comparison of data from this study to data resulting 
from others, we can make some proposals with regard to management of beach litter for the short-and long-term. Beyond the comparison, our study puts forth three major claims about beach litter from land-based sources: (1) influencing bathing beach-goer behaviour in the shortterm should be a high priority for waste managers; (2) plastic items and fragments should be targeted by waste managers for any prevention, management or waste reduction interventions because they are the prevalent material; and (3) the variability of non-plastic litter composition among locations in the Mediterranean (as shown by the statistical analysis) suggests that when targeting waste management actions for these materials, the local context must be better understood. In this discussion we show how the results of our study were interpreted in view of the larger body of literature, to lead to these conclusions.

\subsection{Beach activities and litter}

Our results suggest that activities occurring at bathing beaches contribute the most to beach litter (among items $2 \mathrm{~cm}$ ) when compared to other landside activities particularly artisanal fishing and non-swimming related recreation (e.g., walking). Clean coast indices developed by Munari et al. (2016) using the same technique as for our study (from Alkalay et al., 2007) showed lower (cleaner) indices for 4 out of the five beaches surveyed; three out of five of these could be categorized as largely "undeveloped" (according to Table 1 in Munari et al., 2016). The six Slovenian beaches surveyed by Laglbauer et al. (2014) had CCls from moderately dirty to extremely dirty, with very high amounts of plastic linked to tourism activities. Overall, the latter study's use of the $\mathrm{CCl}$ indicates that geographical distribution of beaches-all of which supported tourist activities - "seemed to be correlated with plastic abundance" (Laglbauer et al., 2014).

The Jisr study's litter density calculations showed an average of 5.1 items m-2 when all the sampling times are taken together on the three beach areas of the town. This is among the highest densities of marine litter reported from beaches throughout the world (see Munari et al., 2016). It is most comparable to measures reported from 5 beaches surveyed in Brazil (Widmer and Hennemann, 2010) and 6 Indonesian beaches (Evans et al., 1995), where there were on average 4.98 items $m-2$ and 4.6 items $m-2$ respectively. Of particular note is that without the Jisr bathing beach site (location $\mathrm{C}$ ), average litter density on the Jisr beach is only 0.21 items $\mathrm{m}-2$. These findings, taken together, suggest that bathing beach activities contribute much of the litter to coastal areas. This suggests that much marine litter could be avoided, if waste managers (or other stakeholders) could enlist beach goers in keeping beaches cleaner during their use.

\subsection{Beach litter composition}

Across the board, in Jisr and on the five beaches surveyed by Munari et al. (2016) and three surveyed over several seasons by Poeta et al. (2016), plastic is the most ubiquitous beach litter item. Furthermore, twenty-three of the 26 studies of beach or "shoreline" litter reviewed by Derraik (2002) found $>50 \%$ of debris items were plastic. Plastics were found to be the most abundant materials for other beach studies conducted in the Mediterranean (e.g., Laglbauer et 
al., 2014) and the most recent ones in Israel (Alkalay et al., 2007; Pasternak et al., 2017). This relates to many other studies contending that plastic fragments are the most common marine litter item (e.g., Slavin et al., 2012; Jambeck et al., 2015).

Plastics are extremely problematic because they are buoyant, persistent and they cause the accumulation of toxins within marine organism (Derraik 2002). They are also vectors of pathogens in the marine environment and aid the dispersal of deleterious invasive species (Gregory 2009; Slavin et al., 2012; Galgani et al., 2015). Derraik's (2002) review of the problem of plastics in the marine environment emphasizes the need for interventions that will address the fundamental cause of plastics in the marine environment such as legislation that will limit plastics use and generation, supportive education efforts as well as economic incentives to reduce plastic use and encourage use and development of biodegradable and photodegradable plastics.

Pasternak et al. (2017) posit that knowing the origin of the marine litter is essential for determining the appropriate actions (intervention) for reducing and preventing such litter. In areas where beach litter originates from sea-borne sources, cleanup activities are needed, and where it originates from land-based sources, educational efforts should be emphasized. This supports conclusions of other research (e.g., Slavin et al., 2012) indicating that when beach litter comes from local visitors, better education and (where appropriate) advocacy could persuade beach users to help clean beach areas. However, these are long-term solutions leading, again, to the consideration of management steps that would enlist beach users to adopt pro-active behaviour during the time that they are using the beach, such as those mentioned by Slavin et al. (2012) or those proposed and studied by de Kort et al. (2008). The latter studied personal norm activation on littering behaviour using different (persuasive) trash can designs.

The importance of waste management measures targeting beach user behaviour is supported by the material types counted during the detailed survey. Polymer material (plastic materials in APM category; see Appendix B) made up over $75 \%$ of the beach litter counted in both April and July surveys. Indistinguishable plastic/polystyrene pieces from 2.5 to $50 \mathrm{~cm}$ in size made up the bulk of this material in both survey periods, $22 \%$ and $14 \%$, respectively. The second most prevalent plastic material was composed of plastic drink bottle caps $-24 \%$ and $16 \%$, respectively for the two survey periods. Drink bottles are frequently used (and brought) by beach goers. While Israel has a beverage bottle deposit program (that covers plastic beverage containers $<1.5$ liter) it does not cover or require plastic cap return. This suggests that a longterm marine litter reduction strategy targeting the consumer product supply chain might include replacing the current detachable lids with non-detachable bottle caps.

Qualitative research carried out in Jisr during the same period as this quantitative study illustrates that the consideration of both short-and long-term measures for beach litter reduction needs to take into account the local socio-economic and socio-institutional context, such as social norms which drive littering behaviour (see Brennan and Portman, 2017). For example, the acceptability of littering public spaces in Arab society (including Jisr) was 
recognised by artisanal fishermen interviewed in Jisr's fishing village (Brennan and Portman, 2017) and is also supported by the literature (see Arafat et al., 2007; Al-Khatib, 2009; Al-Khatib et al., 2009). Such norms could be targeted for a modelled educational intervention. However, there is evidence that general public anti-litter campaigns may not necessarily be effective to prevent littering. For example, in a study measuring the perceptions towards littering of residents in the Palestinian West Bank district of Nablus, Arafat et al. (2007) found that only 5\% of respondents believed that anti-litter awareness campaigns would be the best way to reduce littering behaviour.

From the comparison of marine litter composition noted in our results, looking beyond plastic is important and should be considered when designing short and long term intervention measures as these materials likely make up at least $20 \%$ of the marine debris on beaches of the Mediterranean. Non-plastic litter composition is very context specific as found from the statistical analysis con- ducted between this study and others (namely, Munari et al., 2016; Poeta et al., 2016). Our comparative statistical analysis suggests that a connection between beach litter composition, particularly for non-plastic items, and the socio-economic characteristics of beach-goers as well as to the socio-institutional context would be worth researching further.

The general socio-economic context of the Jisr population is known as well as some of the cultural and socio-institutional con- text (see Brennan and Portman, 2017). However, it would be pre- mature to make any recommendations targeting specific litter items based on these connections without further study, especially since the towns of residence of Jisr beach goers during the crowded bathing season is not known. Furthermore, since responsibility for collection and management of waste on the Jisr coast falls on the township and given the highly contextualized nature of the marine litter problem, any recommended management measures related to the types of materials found along the coast must take into consideration the underlying narratives and politics playing out at a local level. We know from Brennan and Portman (2017) that any technical recommendations targeting specific litter items need to be coupled with a transformation in relationships between local people and the relevant governing institutions at local, regional and national levels in order to bring about change.

Since 2005, the Clean Coast Program, administered by the Israeli Ministry of Environmental Protection in cooperation with the Israel Nature and Parks Authority improves beach cleanliness by using a combination of activities: routine municipal cleanings funded $(70 \%)$ by the program, developing educational activities for all levels (from kindergartens to schools and youth movements), and conducting enforcement against beach littering and against noncooperative municipalities whose coasts were not found clean (Pasternak et al., 2017). However, while education and advocacy should be priority actions for preventing beach users from leaving plastic materials on the beach in the long term, in the short term, encouraging "cleanliness" behaviors through greater trash can use should be a focus and would likely have significant impact. Persuasive designs (see de Kort et al., 2008) that include for example, trash cans that show pictures of marine wildlife strangled by plastic or textual warnings about the harms of plastic bags ingestion by marine mammals, would be worth testing. 
To summarize, based on the findings of the current study alone and what is known about the challenging institutional and related problematic infrastructure context in the town of Jisr (see Brennan and Portman, 2017) local waste management efforts should be directed at changing beach goer behaviour in the short term. This should include encouraging greater trash can use (e.g., using persuasive trash can design, see de Kort et al., 2008) or through greater on-beach enforcement efforts (as supported by the Clean Coast Program). However, the difficult socioeconomic context of Jisr means that compliance and enforcement of fines would be challenging to implement. Further, it is unlikely that such activities would be viable (fiscally) during the off season. In any case, results suggest that during the off-season, litter left by beach goers would be minimal or even non-existent.

Over the long-term, the intervention checklist proposed by Brennan and Portman (2017) could assess the potential effectiveness of marine litter prevention intervention measures and could help formulate efforts that are most appropriate to the local context. Another aspect of waste management that requires further research based on the findings of this study and what is known about the case study site, is that of infrastructure support. For example, beach collection routes between the residential areas of the town and the coastline and short-haul vehicle access need to be addressed both in research and through policy.

\section{Conclusions}

Our in-situ survey of beach litter has uniquely enabled comparison of beach cleanliness and beach litter composition over time and space, both along one coastal town's area and in comparison to other areas in the Mediterranean and the world. Our findings of increased dirtiness at the bathing beach area in Jisr, where activities are sitting, sunbathing, picnicking, playing in the sand and swimming on an official bathing beach, and based on the type of litter found, suggest that beach-goers contribute significantly to marine and coastal litter. Therefore, beach-goers can and should be encouraged to take a more active role in keeping beaches clean, especially to reduce the amount of plastic waste on beaches due to its persistence and observed predominance. Waste managers could target beach-goer behaviour through better trash can design and placement (de Kort et al., 2008) which could then be coupled with increased enforcement for those who fail to use trash receptacles while being sensitive to social, cultural and economic circumstances of the targeted population.

Any planned intervention to target land-based beach litter beyond the short term actions proposed here should be rooted in and should complement the relevant local socio-cultural and socio-institutional context, as pointed out in other papers (e.g., Slavin et al., 2012; Brennan and Portman, 2017). As for non- plastic types of litter both in the short and long terms, we suggest that further research focus on understanding of how local contexts influence the presence or absence of materials and relate these to specific beach-goer activities and characteristics. 


\section{Appendix A - D. Supplementary materials}

Supplementary data associated with this article can be found, in the online version, at https://doi.org/10.1016/j.wasman.2017.07.040.

\section{References}

Abu-Hilal, A., Al-Najjar, T., 2004. Litter pollution on the Jordanian shores of the Gulf of Aqaba (Red Sea). Mar. Environ. Res. 58, 39-63. http://dx.doi.org/10.1016/j.marenvres.2003.12.003.

Al-Khatib, I., 2009. Children's perceptions and behavior with respect to glass littering in developing countries: A case study in Palestine's Nablus district. Waste Manage. 29, 14341437. http://dx.doi.org/10.1016/j.wasman.2008.08.026.

Al-Khatib, I., Arafat, H., Daoud, R., Shwahneh, H., 2009. Enhanced solid waste management by understanding the effects of gender, income, marital status, and religious convictions on attitudes and practices related to street littering in Nablus-Palestinian territory. Waste Manage. 29, 449-455. http://dx.doi.org/10.1016/j.wasman.2008.02.004.

Alkalay, R., Pasternak, G., Zask, A., 2007. Clean-coast index-A new approach for beach cleanliness assessment. Ocean Coast. Manage. 50, 352-362.

http://dx.doi.org/10.1016/j.ocecoaman.2006.10.002.

Arafat, H., Al-Khatib, I., Daoud, R., Shwahneh, H., 2007. Influence of socio-economic factors on street litter generation in the Middle East: effects of education level, age, and type of residence. Waste Manage. Res. 25, 363-370. http://dx.doi.org/10.1177/0734242X07076942.

Arlozorov, M., 2016. How Israel destroyed the place that could have been like Sinai. The Marker. See: http://www.themarker.com/news/1.2958969 (accessed 26.05.16) [in Hebrew].

Barnes, D.K.A., Galgani, F., Thompson, R.C., Barlaz, M., 2009. Accumulation and fragmentation of plastic debris in global environments. Phil. Trans. R. Soc. B. 364, 1985-1998.

http://dx.doi.org/10.1098/rstb.2008.0205.

Brennan, R.E., Portman, M.E., 2017. Situating Arab-Israeli artisanal fishermen's perceptions of marine litter in a socio-institutional and socio-cultural context. Mar. Pollut. Bull. 115, 240-251. http://dx.doi.org/10.1016/i.marpolbul.2016.12.001.

CBS,2013. Central Bureau of Statistics. Characterization and Classification of Geographical Units by the Socio-Economic Level of the Population 2008.

Chen, C.-L., 2015. Regulation and management of marine litter. In: Bergmann, M., Gutow, L., Klages, M. (Eds.), Marine Anthropogenic Litter. Springer, Geneva, Switzerland, pp. 395-428. http://dx.doi.org/10.1007/978-3-319-16510-3. 
Cheshire, A.C., Adler, E., Barbière, J., Cohen, Y., Evans, S., Jarayabhand, S.L., Jeftic, L., Jung, R.T., Kinsey, S., Kusui, E.T., Lavine, I., Manyara, P., Oosterbaan, L., Pereira, M. A., Sheavly, S., Tkalin, A., Varadarajan, S., Wenneker, V., Westphalen G., 2009. UNEP/IOC Guidelines on Survey and Monitoring of Marine Litter No. 186. IOC Technical Series No. 83, UNEP Regional Seas Reports and Studies: pp. 120.

de Kort, Y.A.W., McCalley, L.T., Midden, C.J.H., 2008. Persuasive trash cans: activation of littering norms by design. Environ. Behav. 40, 870-891.

Derraik, J.G.B., 2002. The pollution of the marine environment by plastic debris: a review. Mar. Pollut. Bull. 44, 842-852. http://dx.doi.org/10.1016/S0025-326X(02)00220-5.

European Commission, 2016. Study on specific challenges for a sustainable development of coastal and maritime tourism in Europe Luxembourg. Publ. Office Eur. Union 348.

http://dx.doi.org/10.2826/94993.

European Parliament, 2008. Establishing a framework for community action in the field of marine environmental policy (Marine Strategy Framework Directive) (2008/56/EC). Official Journal of the European Communities L 164, 25.6.2008, 19-38.

http://eurlex.europa.eu/legalcontent/EN/TXT/PDF/?uri=CELEX:32008L0056\&from=en.

Evans, S.M., Dawson, M., Day, J., Frid, C.L.J., Gill, M.E., Pattisina, L.A., Porter, J., 1995. Domestic waste and TBT pollution in coastal areas of Ambon Island (Eastern Indonesia). Mar. Pollut. Bull. 30, 109-115.

Galgani, F., Fleet, D., Van Franeker, J., Katsanevakis, S., Maes, T., Mouat, J., Oosterbaan, L., Poitou, I., Hanke, G., Thompson, R., Amato, E., Birkun, A., Janssen, C., 2010. Marine Strategy Framework Directive, Task Group 10 Report, Marine litter. Luxembourg http://dx.doi.org/10.2788/86941.

Galgani, F., Hanke, G., Maes, T., 2015. Global distribution composition and abundance of marine litter. In: Bergmann, M., Gutow, L., Klages, M. (Eds.), Marine Anthropogenic Litter. Springer, Geneva, Switzerland, pp. 29-56. http://dx.doi.org/10.1007/978-3-319-16510-3.

Golik, A., Gertner, Y., 1992. Litter on the Israeli coastline. Mar. Environ. Res. 33, 1- 15. http://dx.doi.org/10.1016/0141-1136(92)90002-4.

Gregory, M.R., 2009. Environmental implications of plastic debris in marine settingsentanglement, ingestion, smothering, hangers-on, hitch-hiking and alien invasions. Phil. Trans. R. Soc. B. 364, 2013-2025. http://dx.doi.org/10.1098/rstb.2008.0265.

Jambeck, J.R., Geyer, R., Wilcox, C., Siegler, T.R., Perryman, M., Andrady, A., Narayan, R., Law, K.L., 2015. Plastic waste inputs from land into the ocean. Science 347, 768-771. http://dx.doi.org/10.1126/science.1260352. 
European Commission, 2013. Joint Research Centre of the European Commission. Guidance on Monitoring of Marine Litter in European Seas. Luxembourg: 128, http://dx.doi.org/10.2788/99475.

Kamisher, E., 2015. Overlooked Arab-Israeli Beach Town Opens Its Doors to Tourists. Times of Israel. Accessed 13 Feb 2016 http://www.timesofisrael.com/overlooked-arab-israeli-beachtown-opens-its-doors-to-tourists/.

Koutsodendris, A., Papatheodorou, G., Kougiourouki, O., Georgiadis, M., 2008. Benthic marine litter in four Gulfs in Greece, Eastern Mediterranean; abundance, composition and source identification. Estuar. Coast. Shelf Sci. 77, 501-512.

http://dx.doi.org/10.1016/i.ecss.2007.10.011.

Laglbauer, B.J.L., Franco-Santos, R.M., Andreu-Cazenave, M.L., Brunelli, L., Papadatou, M., Palatinus, A., Grego, M., Deprez, T., 2014. Macrodebris and microplastics from beaches in Slovenia. Mar. Pollut. Bull. 89, 356-366. http://dx.doi.org/10.1016/j.marpolbul.2014.09.036.

Laubier, L., 2005. Mediterranean Sea and Humans: Improving a Conflictual Partnership. The Handbook of Environmental Chemistry. A. Saliot. Berlin, Springer. 5 Part K: 3-28.

Munari, C., Corbau, C., Simeoni, U., Mistri, M., 2016. Marine litter on Mediterranean shores: Analysis of composition, spatial distribution and sources in north- western Adriatic beaches. Waste Manage. 49, 483-490. http://dx.doi.org/10.1016/j.wasman.2015.12.010.

Opfer, S., Arthur, C., Lippiatt, S., 2012. NOAA Marine Debris Shoreline Survey Field Guide. National Oceanic and Atmospheric Administration, Washington, D.C.

Pasternak, G., Zviely, D., Ribic, C.A., Ariel, A., Spanier, E., 2017. Sources, composition and spatial distribution of marine debris along the Mediterranean coast of Israel. Mar. Pollut. Bull. 114, 1036-1045. http://dx.doi.org/10.1016/j.marpolbul.2016.11.023.

Poeta, G., Battisti, C., Acosta, A.T.R., 2014. Marine litter in Mediterranean sandy littorals: Spatial distribution patterns along central Italy coastal dunes. Mar. Pollut. Bull. 89, 168-173. http://dx.doi.org/10.1016/j.marpolbul.2014.10.011.

Poeta, G., Battisti, C., Bazzichetto, M., Acosta, A.T.R., 2016. The cotton buds beach: Marine litter assessment along the Tyrrhenian coast of central Italy following the marine strategy framework directive criteria. Mar. Pollut. Bull. 113, 266- 270.

http://dx.doi.org/10.1016/j.marpolbul.2016.09.035.

Ryan, P.G., 2015. A Brief History of Marine Litter Research. In: Bergmann, M., Gutow, L., Klages, M. (Eds.), Marine Anthropogenic Litter. Springer, Geneva, Switzerland, pp. 1-27. http://dx.doi.org/10.1007/978-3-319-16510-3. 
Slavin, C., Grage, A., Campbell, M.L., 2012. Linking social drivers of marine debris with actual marine debris on beaches. Mar. Pollut. Bull. 64, 1580-1588.

http://dx.doi.org/10.1016/j.marpolbul.2012.05.018.

Thiel, M., Hinojosa, I.A., Miranda, L., Pantoja, J.F., Rivadeneira, M.M., Vásquez, N., 2013. Anthropogenic marine debris in the coastal environment: A multi-year comparison between coastal waters and local shores. Mar. Pollut. Bull. 71, 307- 316.

http://dx.doi.org/10.1016/j.marpolbul.2013.01.005.

UN General Assembly, 2012. The future we want. Resolution Adopted by the UN General Assembly on 27 July 2012.

http://www.un.org/disabilities/documents/rio20 outcome document complete.pdf.

UNEP, 2009. Marine Litter: A Global Challenge Nairobi, UNEP pp. 232.

http://oceansandplastics.info/wp-content/uploads/2015/09/OAP-UNEP-2009-Marine-Litter.pdf

UNEP/MAP, 2012. State of the Mediterranean Marine and Coastal Environment. UNEP/MAP, Athens, Barcelona Convention.

UNEP/NOAA, 2011. The Honolulu strategy: a global framework for prevention and management of marine debris. Marine Debris Program, Silver Spring, Maryland, USA, The United Nations Environment Program (UNEP); National Oceanic and Atmospheric Administration (NOAA) https://marinedebris.noaa.gov/sites/default/files/publications-files/Honolulu Strategy.pdf.

Widmer, W.M., Hennemann, M.C., 2010. Marine debris in the Island of Santa Catarina, South Brazil: spatial patterns, composition, and biological aspects. J. Coast. Res. 26, 993-1000.

http://dx.doi.org/10.2112/JCOASTRES-D-09-00072.1. 